\title{
ENZYMATIC ZONULOLYSIS IN CATARACT SURGERY* A REVIEW OF 432 CASES
}

\author{
BY \\ J. M. PAHWA \\ Eye Hospital, Sitapur, India
}

SiNCE the introduction of alpha-chymotrypsin (ACT) by Barraquer (1958a,b) as a zonulolytic agent to facilitate intracapsular cataract extraction, it has been widely used by surgeons in many countries.

It is a proteolytic enzyme derived from the bovine pancreas, but its exact mechanism or mode of action is not clear. According to Barraquer it has specific action on the zonule and other structures are not affected, but according to Salmony (1959) its effect is not restricted specifically to the zonule, but it may also attack other structures such as the vitreous body which is developmentally similar to the zonule. Salmony investigated its proteolytic effect on tissues other than the zonular fibres through its ability to liberate amino acid from samples of aqueous, lens, and vitreous homogenates with which it was incubated. Bedrossian (1959), while experimenting on animals, came to the conclusion that the enzyme weakens the zonular fibres or its attachments but does not completely dissolve them. He thought that the healing of the corneal wound was not affected, but felt that the action of the enzyme might not be as selective as was claimed.

Pieces of eye tissue submerged in a 1 in 5,000 solution of the enzyme for several hours were found to show no alteration even on microscopic histological examination (Barraquer, 1959), and the solution of the problem of the enzyme's mechanism of action may probably lie in the realm of biochemical and ultra-microscopic study. A preliminary study of human eyes and eyes of Rhesus monkeys by electron microscopy reveals that the anterior lens capsule has three distinct layers, the outermost of which is continuous with the zonular fibres (pericapsular membrane) and ceases to be apparent after contact with alpha-chymotrypsin. The zonule breaks down into clusters and fragments of relatively uniform length and arrangement, while the ciliary epithelium and internal limiting membrane remain unchanged.

It is widely agreed that cataract extraction is facilitated by the use of this enzyme (Cogan, Symons, and Gibbs, 1959; Ainslie, 1959; Zorab, 1959). Paufique (1959), reviewing 200 cases, recommended it for cases in which unusual zonular resistance was expected; he further remarked that it should not be used for patients under the age of 10 years. Though Barraquer (1959) has used it in extracting congenital cataracts, his youngest patient being

* Received for publication October 31, 1960. 
4 years old, he has also pointed out the dangers of attempting extraction if the enzyme has not acted long enough. Arruga (1958) recommended a 1 in 10,000 solution. Rizzuti (1959), who had used it in 32 cases, stated that a well-dilated pupil, absence of excessive hyphaema, and a hypotonic eye will produce a more satisfactory effect; in one of two cases of congenital cataract, the chemical zonuloysis had little or no effect and resulted in vitreous loss.

\section{Indications for Use}

(1) In juvenile and pre-senile cataracts in which the suspensory ligament is fairly strong.

(2) In congenital and traumatic cataracts in patients over the age of 20 years. It should not be used in patients younger than this because the zonule is not the main problem; there is such a dense attachment of the anterior vitreous face to the posterior lens capsule that intracapsular extraction becomes hazardous and the incidence of vitreous loss is apt to be high.

(3) In high myopes, in which the risk of subsequent retinal detachment may be reduced by avoiding pressure or drag on the ciliary body and subsequent vitreous loss.

(4) In cases in which one eye has been lost by retinal detachment, preferably after a prophylactic diathermic barrage, as advocated by Franceschetti (1955) and Callahan (1959), has been undertaken 2 or 3 months before.

(5) In one-eyed persons, because it makes the operation safer.

\section{Present Series of Cases}

The present paper describes the results in a series of 432 unselected cases.

Material.-There were 290 males and 142 females. Their age groups were as follows:

TABLE I

\begin{tabular}{c|c}
\hline Age Group (yrs) & No. of Cases \\
\hline $10-20$ & 5 \\
$21-30$ & 64 \\
$31-40$ & 128 \\
$41-50$ & 119 \\
$51-70$ & 116 \\
\hline Total & 432 \\
\hline
\end{tabular}

Preparations Used.-Chymar-Zon (Chemo-Pharma) was used in fourteen cases, and Quimotrase (Pevya) in the remaining 418 cases.

The latter was used in different concentrations, but we found the 1 in 5,000 solution to be efficacious and safe and it is therefore recommended, but in senile 
cases a 1 in 10,000 solution may be strong enough because the zonule is not so tough. $2 \mathrm{ml}$. was found to be enough for most cases, but in very young patients the amount may be increased to $4 \mathrm{ml}$. One should wait for at least 3 minutes before attempting to remove the lens as it takes at least that long for the full action to be exerted on the zonule.

Our experience with Chymar-Zon is more limited, but 0.5 to $0.75 \mathrm{ml}$. (50-75 units) was found to be an effective amount.

Surgical Technique.-The premedication of the patient by Largactil and Gardenal and preparation by local anaesthesia and akinesia is the same as for any case of cataract extraction. Moderate dilatation of the pupil so that the enzyme can be injected well behind the iris to reach the zonule is preferable. A single pre-placed conjunctivo-episclero-limbal suture at 12 o'clock is used in all cases; this can be supplemented by two or more additional sutures in the few cases in which there is some tendency to vitreous loss or iris prolapse or the patient is un-cooperative.

The usual incision from 9 to 3 o'clock with a conjunctival frill is made with a von Graefe knife without cutting the pre-placed stitch. The keratome and scissors method is reserved for cases with a shallow anterior chamber or deeply set en-ophthalmic eyes. After the von Graefe section, alpha-chymotrypsin 1 in 5,000 solution freshly prepared is injected all round into the posterior chamber by means of a light 2-ml. syringe fitted with a long lacrimal blunt needle or cannula, thus flooding the subiridic space. Recently, we have started using curved rounded multi-holed cannulae, but I still prefer the former. Posterior synechiae if present are first dealt with by the iris repositor as the enzyme has no effect on them. Now one must wait for at least 3 minutes, during which time the zonule is weakened and the lens shows increased sphericity and appears to come forward. During this time one or two peripheral iridectomies can be done and if necessary, particularly in young subjects, a further injection of the enzyme can be made behind the iris through the iris coloboma. After 3 minutes the anterior chamber is washed with saline solution to remove any excess of the active enzyme.

Removal of the Lens.-The following methods were used in our 432 cases:

(1) Arruga's intracapsular forceps (62)

(2) Suction method (73)

(a) 20-ml. syringe fitted with a Barraquer ventouse through a long tube (41)

(b) Barraquer's erisophake (32)

(3) Smith's method (297)

I prefer Smith's method of expression as I have found it to be safer and followed by fewer complications. Gentle pressure is applied to the limbus at 6 o'clock with a lens hook or Daviel spoon, and gentle counter-pressure is applied with an iris repositor at 12 o'clock; the lens is thus expressed directly. Removing the upper pole first is easier than tumbling.

If intracapsular forceps are used, one should be very gentle and cases of slippery capsule and intumescent cataract should be avoided because of the risk of dislocating the lens by undue pressure. If a weak 1 in 10,000 solution of the enzyme is used, however, the intracapsular forceps are to be recommended. 
Conclusion.-After the lens has been removed, the chamber can be washed with a 1 in 10,000 solution of acetylcholine, but this I do not consider essential, and it may even disturb the anterior face of the vitreous and injure the corneal endothelium.

The iris is now replaced, the pre-placed suture is tied, with extra ones if necessary, and the conjunctival frill is smoothed over the suture lines.

A subconjunctival injection of penicillin is given and a drop each of eserine and pilocarpine is instilled. Only the operated eye is bandaged and the patient is sent back to the ward.

\section{Complications}

In 99 cases complications were encountered. Some of these results were compared with those in another series of cases in which the enzyme was not used (Table II):

TABLE II

\begin{tabular}{l|c|c}
\hline \multicolumn{1}{c|}{$\begin{array}{c}\text { Complications as Percentage of Total No. } \\
\text { of Patients }\end{array}$} & Enzyme used \\
\cline { 2 - 3 } & Yes & No \\
\hline Vitreous loss (14) & $3 \cdot 01$ & $1 \cdot 2$ \\
Striate keratitis (33) & $7 \cdot 84$ & $0 \cdot 8$ \\
Iris prolapse (9) & $2 \cdot 08$ & $1 \cdot 2$ \\
Hyphaema (14) & $3 \cdot 01$ & $2 \cdot 3$ \\
Rupture of capsule (9) & $2 \cdot 1$ & $5 \cdot 2$ \\
Non-formation of anterior chamber (9) & $2 \cdot 08$ & 1.0 \\
\hline
\end{tabular}

(1) Vitreous Loss (14 cases; 3 per cent).-This occurred mostly in our earlier cases irrespective of age, before the technique was perfected. Its incidence was less in the lower age groups (20-30 years, one case; 31 to 40 years, two cases; 40 to 70 years, eleven cases). The vitreous presented soon after the injection of the enzyme and before the lens could be extracted in two cases; this may possibly have been due to subluxation of lens by too much force or uncontrolled pressure of the cannula. One of these cases was a congenital cataract and another was a traumatic cataract. In all these cases the amount lost was very slight, and in some the only sign was that the anterior chamber became deep. In one myopic case the vitreous was of fluid consistency. If the early cases are excluded, vitreous loss did not occur more often than in the non-enzyme cases, and it should not be forgotten that this series includes many young patients and myopes in whom vitreous loss is bound to be somewhat higher.

Comparing this with other reported series, we find that Cogan and others (1959) had two cases of vitreous loss in 122 eyes, Ainslie (1959) had no vitreous loss in 32 eyes, Murray and Drance (1960) reported it in 5 per cent. of their cases, and Townes (1960) in two eyes out of 67.

Most of our cases were also studied under the slit lamp at the time of discharge from hospital, and the anterior vitreous surface was found to be intact. 
(2) Keratitis and Corneal Vascularization (33 cases; 7.8 per cent.).-This was nearly nine times more frequent than in the non-enzyme series, but mostly disappeared within 8 to 10 days. The inflammation was worse and persisted longer if accompanied by vitreous loss, and in two cases it persisted for nearly 6 weeks and took a long time to clear up. Cogan (1959) had one case of prolonged corneal infiltration. In the series of 26 eyes reported by Zorab (1959), there was one case of Fuchs's dystrophy which deteriorated rapidly after surgery. Ainslie (1959) had sixteen eyes out of 32 cases, which showed a marked striate keratitis for 3 weeks. Similarly Townes (1960) observed it in 10 per cent. of his cases, Drance, Murray, and Smith (1960) reported striate keratopathy with corneal oedema in most of the cases in which the enzyme was used, and Hill (1959) reported corneal vascularization after the use of the enzyme in a 31-year-old man.

One of my patients who had trachoma developed corneal vascularization and oedema, which were perhaps accelerated by the previous trachomatous process.

Whether the enzyme had anything to do with the corneal oedema or keratitis is not clear. As it occurred less frequently in those treated by the Smith method and more often in those treated by the suction method, it might have been due to a mechanical injury of the endothelium. Kara (1960) suggested that it might be caused by the neurotoxic action of a strong concentration of alpha-chymotrypsin on exposed nerve endings in the line of the incision. In cases of vitreous loss, it might have been caused by contact with the corneal endothelium.

(3) Iris Prolapse (9 cases; 2.03 per cent.).-This was slightly more than in the non-enzyme series ( 1.2 per cent.). In two cases vitreous was also lost during operation. The iris prolapse was seen on the second or third day in all but two cases which were noticed on the fifth and sixth day; in one of the latter it was accompanied by marked hyphaema.

The prolapsed iris was excised, except in one case in which a slight prolapse was seen on the fifth day and was covered by conjunctiva and left alone. Cogan and others (1959) had six iris prolapses in 122 cases and in one the prolapse occurred as late as the 21 st day. Orr (1959) reported one iris prolapse in fifty eyes, but the time interval was not stated. Townes (1960) reported six examples in his 67 cases, but the prolapse usually occurred between the sutures. A re-opening of the wound without iris prolapse did not occur in our series, but Townes reported four cases in patients over 70 years of age (two in hospital and two after discharge), in all of which the wound required resuturing.

These results suggest that the enzyme may interfere with wound healing, but I agree with Bedrossian (1959) who found no change in the wound union in his experimental work. On the other hand, Troutman (1958) suggested that corneal wound healing should be further studied and cited three instances of delayed wound rupture in 197 cases reported by Barraquer. Murray and Drance (1960) also reported a case of delayed iris prolapse occurring on the fifteenth day.

(4) Hyphaema (14 cases; 3.01 per cent.)-This was slightly more than in the non-enzyme group ( 2.03 per cent.). The hyphaema was not severe and occurred mostly on the fifth and sixth day. One patient was diabetic. François (1958) remarked at the All-India Ophthalmic Conference held at Trivandrum that it was one of his chief complications. Murray and Drance (1960) had one hyphaema in 
42 cases, and also mentioned that an eye surgeon known to them had reported that extensive post-operative hyphaema had occurred in the first three cases in which he had used the enzyme. Cogan and others (1959) had one severe hyphaema in 122 cases, Ainslie (1959) had one in 32 cases. The exact cause is not known, but it may be presumed that the enzyme may cause a fibrolysis at the ends of the small severed iris vessels after they have been sealed by a normal blood clot.

(5) Rupture of the Capsule ( 9 cases; $2 \cdot 1$ per cent.).-As might be expected, there were many more ruptured capsules in the non-enzyme series than in the enzyme series. This is not a serious complication, but if there is concomitant vitreous loss, there may be a severe reaction and keratitis and iritis may supervene.

Rizzuti (1959) had four ruptured capsules in 32 eyes, Cogan and others (1959) had ten in 122 eyes, Orr (1959) one in fifty eyes, and Townes (1960) five in 67 eyes.

(6) Dislocation of the Lens (6 cases).-This occurred mostly in the earlier cases and was perhaps due to undue pressure during the injection of the enzyme or by the intracapsular forceps. In three cases the lens showed a marked tendency to spontaneous delivery soon after the injection because of complete lysis of the zonule helped by straining or increased intravitreal pressure. Murray and Drance (1960) reported that in many of their cases vitreous was lost immediately after the injection before the eye was touched. Whether this was due to the enzyme or to the delay before starting surgery was not clear, but they recommended that the lens should be fixed soon after the injection of enzyme. They also reported a case of complete dislocation of the lens into the vitreous, and its removal with a vectis.

(7) Fragmentation of Iris Pigment Epithelium (3 cases).-This is not a serious complication. Kara (1960) found that it occurred more often with Quimotrase. No case of pigmentary glaucoma has been reported. Barraquer (1959) thought that it was not directly related to the alpha-chymotrypsin and might be avoided by a careful technique.

(8) Non-formation of Anterior Chamber (9 cases; 2.08 per cent.).-In each case this occurred within the first 8 post-operative days, and it was twice as frequent as in the non-enzyme series. The wound healing was normal in each case. Three had choroidal detachment. Four responded very well to Diamox and the anterior chamber was re-formed within 48 to 72 hours. One had severestriate keratitis which may have predisposed to the formation of adhesions between the iris and cornea; this case was treated by air injection but later developed secondary glaucoma. The wound healing was normal and no delayed re-opening of the wound was noticed in any case although only one conjunctivo-episclero-limbal fine silk suture was used.

Townes (1960) had seven cases out of 67, three with iris prolapse and two with wounds re-opening, Murray and Drance (1960) had one case out of 42, and Valerio (1959) reported late flattening of the anterior chamber in eleven of his seventy cases. This has not been a serious matter in our series and when it occurred was only of short duration (Mehrey and Pahwa, 1960). 
(9) Other Complications.-There was no case of infection and uveitis was rare. In one case of iritis in which the capsule had ruptured and there was also vitreous loss kerato-iritis developed; this took a long time to clear up but the ultimate visual acuity was 6/12. Townes (1960) thought that the uveitis was unrelated to the use of alpha-chymotrypsin. Murray and Drance (1960) had endophthalmitis in their first case, which was later controlled, and Cogan and others (1959) reported three cases in which a severe iritis with hypopyon developed, but whether the enzyme caused the endophthalmitis is debatable. The injection of any solution into the eye may increase the chance of infection, and for this reason a perfectly sterile and balanced salt solution which can have no cytotoxic effect on intra-ocular structures should be used.

Secondary glaucoma was noted only in two cases; one was due to delayed formation of the anterior chamber and in the other the tendency may have been present before the operation.

Retinal detachment occurred in one patient who was highly myopic ( $-14 \mathrm{D})$ and who had a slight loss of fluid vitreous during the operation. The shallow detachment was seen in the lower part 7 weeks after the operation but subsided after a period of rest in bed. It later developed into an almost total detachment 7 months after the operation. Murray and Drance (1960) reported one case out of 45 in a patient who was also a diabetic; total detachment occurred after 6 weeks and was treated by scleral buckling. Zorab (1959) had one extensive retinal detachment associated with a vitreous haemorrhage on the fourth day.

One of our patients had an uncomplicated extraction, but the vision did not improve beyond 6/60. There was no abnormality except some mild macular oedema which did not respond well to vasodilators. The other eye was operated on without the use of enzyme and the result was a visual acuity of $6 / 6$.

\section{Discussion}

The use of this enzyme marks a great advance in cataract surgery by weakening the zonule. In younger patients complications were significantly less when the enzyme was used, but in such cases the dose of the 1 in 5,000 solution may be increased. In patients less than 20 years old and in cases of congenital cataract the enzyme should not be used, as serious complications have been reported (Troutman, 1958; Cogan and others, 1959; Paufique, 1959). Delivery of the lens was effected by expression by Smith's method.

Some complications which are said to occur more frequently with alphachymotrypsin include severe corneal oedema, hyphaema, iris prolapse, re-opening of the wound, and early shallow anterior chamber. The last two can be attributed to the retarding effect of alpha-chymotrypsin on wound healing (Fink, Bernstein, and Binkhorst, 1960). In our series wound re-opening and excessive iris prolapse were not noted. The enzyme has no effect on chromic catgut, but Altamirano and Callahan (1959) advise a minimum of five sutures. I still use a single pre-placed conjunctivo-episclero-limbal silk suture which is removed on the ninth day, and no case of delayed wound opening was noticed. 


\section{Conclusions}

(1) There is evidence that alpha-chymotrypsin retards wound healing, so that plain catgut should not be used in suturing the incision; chromic catgut is safe and silk sutures perhaps safer still.

(2) Striate keratitis, iris prolapse, and non-formation of the anterior chamber is seen more frequently than with other methods. Moreover, if these complications, particularly vitreous loss and iris prolapse ensue, the healing will be much more difficult than when no enzyme is used.

(3) Alpha-chymotrypsin should not be used in patients below the age of 20 years.

(4) It should not be used as a routine in old people because of the many complications, especially as the lens can be so easily extracted in such cases by Arruga's intracapsular forceps.

(5) It should be used in juvenile cases of cataract, and in high myopes. In the latter it will be still preferable to make a diathermic barrage all round as recommended by Callahan (1959) 3 months before the operation. This is especially indicated if one eye has already been lost by retinal detachment.

(6) It should also be used for cases in which difficulty in the intra-capsular procedure is anticipated.

\section{REFERENCES}

AINSLIE, D. (1959). Brit. J. Ophthal., 43, 200.

Altamirano, R., and Callaghan, A. (1959). Sth. med. J. (Bgham, Ala.), 52, 1327-1330.

ARRUGA, H. (1958). Arch. Soc. oftal. hisp.-amer., 18, 1073.

BARRAQUer, J. (1958a). "Zonulolysis enzymatica." Communication to the Real Academia Medica de Barcelona. April.

(1958b). "Enzymatic Zonulolysis", in "Highlights of Ophthalmology", by B. F. Boyd, p. 223.

(1959). Proc. roy. Soc. Med., 52, 973.

Bedrossian, R. H. (1959). A.M.A. Arch. Ophthal., $62,216$.

Callahan, A. (1959). Amer. J. Ophthal., 47, 576.

Cogan, J. E. H. (1959). Trans. ophthal. Soc. U.K., 79, 591. SYmons, H. M., and GiBBs, D. C. (1959). Brit. J. Ophthal., 43, 193.

Drance, S. M., Murray, R. G., and Smith, T. (1960). Amer. J. Ophthal., 49, 64.

Fink, A. I., BERnSteIn, H. N., and BinkHorst, D. (1960). A.M.A. Arch. Ophthal., 64, 104.

FranÇesChetTI, A. (1955). Amer. J. Ophthal., 39, 189.

FrançOIs, J. (1958). All-India Ophthalmic Society Conference, Trivandrum.

HILL, D. W. (1959). Brit. J. Ophthal., 43, 325.

KaRA, G. B. (1960). A.M.A. Arch. Ophthal., 63, 122.

Mehrey, M. P., and PaHWA, J. M. (1960). Ophthalmologica (Basel), 140, 22.

Murray, R. G., and Drance, S. M. (1960). A.M.A. Arch. Ophthal., 63, 910.

ORR, H. C. (1959). Brit. J. Ophthal., 43, 330.

PAufiQue, L. (1959). Soc. Ophtal. Lyon, 25, January.

RizzUTi, A. B. (1959). A.M.A. Arch. Ophthal., 61, 135.

SAlMONY, D. (1959). Brit. J. Ophthal., 43, 321.

TOWNES, C. D. (1960). A.M.A. Arch. Ophthal., 64, 108.

Troutman, R. C. (1958). Trans. Amer. Acad. Ophthal. Otolaryng., 62, 875.

VALERIO, M. (1959). An. Inst. Barraquer, 1, 149.

Zorab, E. C. (1959). Brit. J. Ophthal., 43, 202. 